\title{
Hip and Groin Pain: Radiological Assessment
}

\author{
Peter J. MacMahon ${ }^{*}, 1$, Philip A. Hodnett ${ }^{1}$, George C. Koulouris ${ }^{2}$, Stephen J. Eustace ${ }^{1}$ and \\ Eoin C. Kavanagh ${ }^{1}$
}

${ }^{I}$ Department of Radiology, Mater Misericordiae University Hospital, Dublin 7, Ireland

${ }^{2}$ Victoria House Medical Imaging Prahran, Victoria, Australia

\begin{abstract}
Hip and groin pain are commonly encountered complaints in orthopedic practice. The diagnosis can be difficult to establish based on the complex interconnected anatomy at the pubic symphysis and around the hip. In addition patients can present with varied pathology, such as labral and cartilaginous injuries, surrounding soft tissue derangement involving muscles or tendons and osseous abnormalities. The differential diagnosis is therefore broad and diagnostic imaging is crucial in reaching the correct diagnosis, thus allowing appropriate therapy to be instituted. This article will review the relevant anatomy, differential diagnoses and important imaging findings encountered in chronic hip pain and overuse injuries of the groin.
\end{abstract}

Keywords: Groin, hip, MRI, athletic pubalgia, tendon, ligament.

\section{INTRODUCTION}

Athletic injuries of the hip and groin can require extensive rehabilitation time. Timely and accurate diagnosis is thus critical in the development of an effective treatment plan. Epidemiologic studies have shown that injuries to the hip region account for approximately 5 to $9 \%$ of sports injuries in high school athletes $[1,2]$. Hip injuries likely relate to the fact that loads of up to eight times body weight have been recorded in the hip joint during jogging, with potentially greater loads present during vigorous athletic competition [3]. Groin pain is typically an overuse injury due to excessive athletic activity accounting for approximately 2 to $18 \%$ of all sports injuries [4-6]. Indeed, any sport that is associated with rapid changes in speed and direction, and/or kicking activity in particular, have higher rates of groin and hip injury. Such sports include ice hockey, American football, Australian Rules football, fencing, track and field events, as well as soccer [7-9].

The underlying processes that lead to groin injury are complicated, varied and incompletely understood. Due to the difficulty in obtaining an accurate diagnosis, patient management and outcomes have historically been unpredictable [9-11].

In clinical practice, the term "athletic pubalgia" is a general term used to describe exertional pubic or groin pain [12]. Most authors have concluded that the most common causes of groin pain are adductor longus injury, adductorrectus abdominis dysfunction, osteitis pubis and the "sportsman's hernia", see Table 1 [13-16]. The differential diagnosis of hip pain is diverse and includes entities such as stress fracture, avulsive injuries, snapping hip syndrome,

*Address correspondence to this author at the Department of Radiology, Mater Misericordiae University Hospital, Eccles Street, Dublin 7, Ireland; Tel: +353 868157084; Fax: +353 8034791;

E-mail: petermacmahon@yahoo.com

\section{Table 1. Common Causes of Groin Pain}

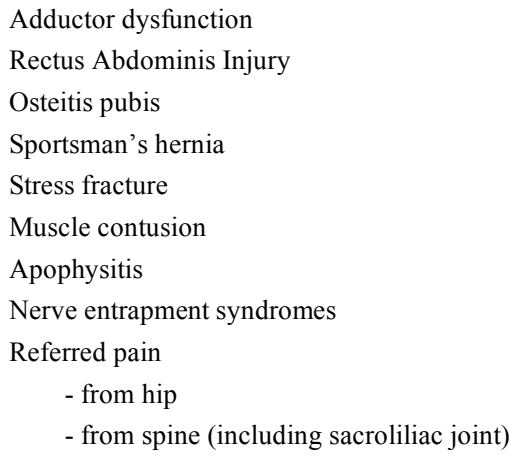

iliopsoas bursitis, femoroacetabular impingement (FAI) syndrome, tendinosis and tears of the gluteal musculature.

This article reviews the anatomy, etiology and imaging appearances of these entities with an emphasis on the importance of Magnetic Resonance Imaging (MRI).

\section{ANATOMY}

\section{Groin Anatomy}

The pubic symphysis is composed of the paired pubic bones and the intervening fibrocartilaginous articular disc [17]. The medial articular surface of the pubis is grooved and lined by hyaline cartilage. A thin physiological cleft (also called the primary cleft) can be located superiorly within the fibrocartilaginous disc [18]. The pubic tubercle arises from the lateral aspect of the pubic crest, a bony projection over the anterior surface of the pubic body. A thin superior pubic ligament bridges the pubic tubercles, which is partly formed from posterior rectus abdominis muscle fascia. The arcuate (inferior pubic) ligament is an important stabilising structure that forms a strong fibrous arch along the inferior margin of the symphyseal joint. The arcuate ligament blends with the 
subjacent fibrocartilage disc [16]. A thin anterior pubic ligament also attaches to the underlying articular disc and blends with interconnecting fibrous tissue anteriorly formed from tendons and ligaments.

The rectus abdominis muscle acts as a stabilizer of the anterior abdominal wall, originating lateral to the pubic symphysis along the pubic crest. The adductor longus tendon acts to allow thigh adduction and to stabilize the anterior pelvis during the swing phase of the gait [19]. It originates just inferior and in line with the rectus abdominis origin along the most anterior aspect of the pubis and just inferior to the pubic crest. The adductor longus tendon is usually entirely tendinous anteriorly, with an accessory muscular origin posterolaterally in $25 \%$ of patients $[17,19]$. Importantly the origins of the rectus abdominis and the adductor longus tendons merge anterior to the pubis to form a common structure that is firmly adherent to the pre-pubic surface $[16,20]$. The adjacent gracilis and adductor brevis tendons are variably fused with each other and adductor longus as they arise from the inferior pubic body, anterior pubic ligament and arcuate ligament [21]. Further to this, the rectus abdominis muscle and sheath extends across the anterior pubic surface to interdigitate with the tendon fibres that give origin to the adductor muscle compartment, resulting in the formation of a common adductor-rectus abdominis origin.

In summary the anterior aspect of the pubis acts as a common origin for important muscular structures around the pubic symphysis. Tissue in this pre-pubic region not only interconnects the adductor tendons and rectus abdominis, but also integrates with the para-symphyseal support ligaments and elements of the inguinal canal. In addition there appears to be a fibrocartilaginous component to this pre-pubic tissue continuous with articular disk. This complex structure acts a central anchor point and is formed by interconnecting fibers of the adductors, rectus abdominis, external oblique, inguinal ligament, anterior pubic ligament, arcuate ligament and fibrocartilaginous disc. This anatomical knowledge is crucial to understanding the mechanism of groin injuries and thus formulating an accurate diagnosis.

The complex inter-related anatomy of this anatomical area has led to the use of confusing diagnoses and terminology when describing the etiology of groin pain, which are almost certain to be linked pathophysiologically.

\section{Hip Anatomy}

The hip joint is a ball and socket joint allowing motion in a wide range of directions. The femoral head is covered by the spherical acetabular socket except at its inferomedial aspect where the socket is deficient. The transverse acetabular ligament spans this deficiency with stability of the joint in part due to the relationship of the acetabulum to the femur, with the acetabulum directed anterolaterally relative to the pelvis and the femoral neck directed posteriorly. Articular cartilage lines the femoral head except for the fovea capitus, a depression identified on the central surface of the femoral head. The ligamentum teres arises from this central depression before coursing inferiorly to insert onto the transverse ligament. Horseshoe shaped articular cartilage, the lunate cartilage, lines the acetabulum except for the central portion of the acetabulum. The acetabular fossa is filled with fibrofatty tissue and is lined by synovium.

A fibrocartilaginous labrum, thicker posterosuperiorly than anteroinferiorly lines the acetabulum, attached directly to the bony rim and blends with the transverse ligament at the acetabular notch [22]. The hip capsule inserts onto the acetabular rim directly. Superiorly, the hip joint capsule inserts above the labrum creating a perilabral recess with a smaller recess between the labrum and joint capsule formed by the capsular insertion along anterior and posterior joint lines [23]. The hip is further stabilized by capsular thickenings comprising the iliofemoral, pubofemoral and ischiofemoral ligaments.

\section{IMAGING}

\section{Imaging of Groin Pain}

A catch-all term for all the causes of groin pain is "athletic pubalgia" [16]. This term is the preferred label that refers to a spectrum of musculoskeletal injuries that occur in and around the pubic symphysis and that share similar mechanisms of injury and common clinical manifestations [16]. The literature supports that the most common causes of athletic pubalgia originate from the muscles and tendons of the adductor group and rectus abdominis, pubic symphysis (osteitis pubis) and the inguinal wall $[4,16,17]$.

Groin pain in athletes can be acute (secondary to a single event), chronic (secondary to altered biomechanical load and repetitive microtrauma) or a combination of the two. It can be postulated that an injury to a structure inserting into prepubic aponeurotic tissues (typically adductor longus or rectus abdominis) may secondarily affect remaining structures that rely on the aponeurotic complex for their integrity.

\section{Common Adductor-Rectus Abdominis Injury}

Though there are many causes of athletic pubalgia described, most authors conclude that the most common cause of groin pain in athletes is adductor dysfunction as this is the strongest muscle group acting on the pubic symphysis $[24,25]$. Though the exact frequency of injury to specific structures around the pubic symphysis will be sport specific, injury to the adductor longus is consistently the most common, especially in soccer players [24]. The prevalence of adductor dysfunction ranges from $44 \%$ to $60 \%$ in published series $[9,26,27]$. There are a number of risk factors for adductor injury including a history of strain and low levels of sport-specific pre-season training [28]. As the adductor longus muscle is the most frequently injured muscle, inflammatory change in the para-symphseal bone (osteitis pubis) may co-exist. Radiographs are generally normal however sometimes enthesopathy, ill definition of cortical bone at the tendon origin, is visible. Ongoing healing with repeated injury can lead to a mixed sclerotic-lytic appearance in severe cases (which is separate to osteitis pubis, discussed below). Sonography can also be utilized to diagnose tendinosis of the adductor longus distal to its origin. Tendinosis manifest as hypo-echogenicity to the tendon, with tendon expansion seen in more severe injuries. With careful sonographic examination, a partial thickness or full thickness tear can be visualized [29]. A rectus abdominis injury at its origin from the pubic symphysis is also 
described as a source of pubic pain in athletes with similar clinical and physical findings seen in adductor origin injury [25]. As Gibbon et al. described in 1999, a common adductor-rectus abdominis (CA-RA) origin exists as an anatomical and functional unit anterior to the pubis [26]. This has been referred to as an aponeurosis by many authors $[16,20,24]$. Magnetic Resonance (MR) imaging is the modality of choice in the depiction of adductor tendon, rectus abdominis tendon and aponeurotic complex injuries (Fig. 1). Fat-saturated fluid sensitive MR sequences in the axial oblique plain will best demonstrate acute or chronic adductor muscle injuries and coronal sequences are ideal for the detection of the "secondary cleft" sign adjacent to the pubic symphysis (Fig. 2). The "secondary cleft" sign is manifest as extension of fluid-bright signal external to the pubic symphysis to one or both sides (the side of extension has been shown to correlate with symptoms) and is continuous with the primary intra-articular cleft [30]. The exact anatomy of this sign has yet to be formally elucidated but it likely represents a tear or partial avulsion of the adductor longus origin where it gains origin from the prepubic aponeurotic tissues. The aponeurotic injury likely extends into the underlying fibrocartilage disc, disrupting the integrity of the anterior aspect of the physiological cleft (if present). In this circumstance, symphyseal cleft injection can demonstrate extension of contrast from the physiological cleft into the "secondary cleft" [30]. Tendinosis manifests as ill-defined increased signal on T2 weighted imaging, with partial thickness tears manifests as focal areas of T2 hyperintensity similar to fluid signal. Gadolinium enhancement, if used, has been shown to correlate with the symptomatic side [31]. Muscular strains most commonly occur at the musculotendinous junction of the adductor longus, normally anteriorly. In severe injury a retracted tendon can be visualized on MR imaging (Fig. 3).

\section{Osteitis Pubis}

Osteitis pubis is a painful condition affecting the pubic symphysis that likely represents an inflammatory response, secondary to altered biomechanics and loading at the symphysis. It is most frequently seen in athletes involved in kicking sports such as soccer and Australian Rules football. Osteitis pubis can occur in isolation however it is commonly associated with other pathological entities around the pubic symphysis such as adductor and rectus abdominis injuries $[24,25,30]$ (Fig. 4).

Imaging appearances were first described on plain radiography as irregularity of the subchondral bone, erosions, and fragmentation with areas of mixed sclerosis and lysis. If very severe there may be widening of the symphysis. A craniocaudal discrepancy of inferior pubic margins on stress radiography is diagnostic of symphyseal instability. Radioisotope bone scans show increased uptake of radiotracer about the pubic symphysis [32] (Fig. 5). Hyperintense signal change on fluid sensitive sequences in the bone marrow adjacent to the symphysis at MRI are presumed to represent bone marrow edema and the earliest manifestation of osteitis pubis. As has been mentioned, the pubic symphysis is intimately connected with a pre-pubic aponeurotic complex of tissues that acts as the origin for many structures around the symphysis. Chronic repetitive injury of a component of this aponeurotic complex may lead to instability at the pubic symphysis and a stress response with resultant edema in the para-symphyseal subchondral bone. If the bone edema is preferentially unilateral, this likely reflects direct traction effects from a more focal injury. Importantly, osteitis pubis with bone marrow edema is usually seen in symptomatic patients and predicts pre-season training restriction $[15,24]$.

(a)

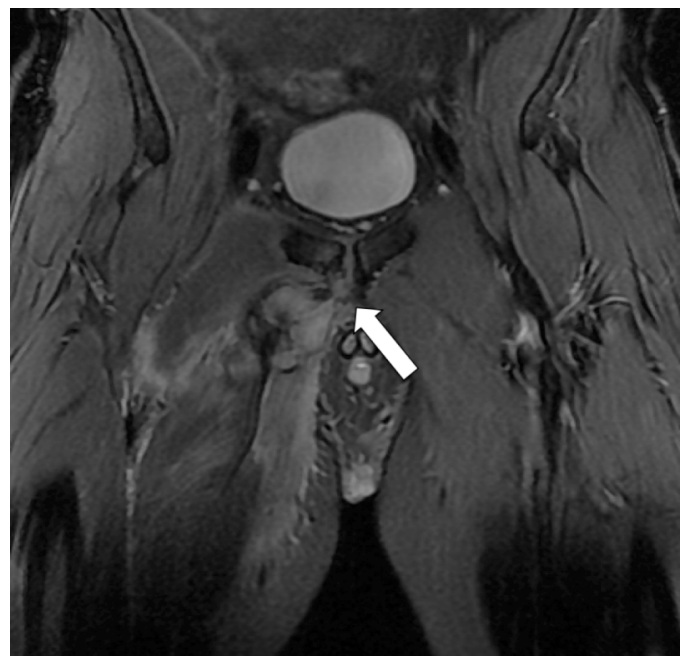

(b)

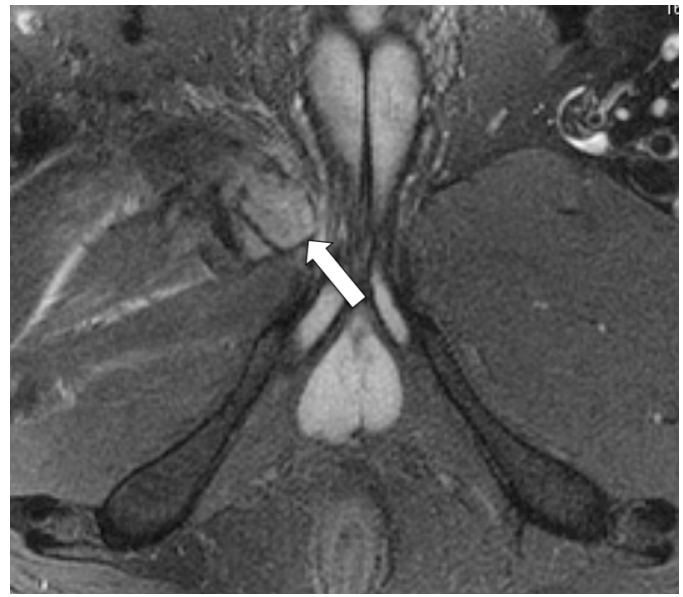

Fig. (1). (a) Coronal fat saturated T2 weighted MRI. Large acute proximal right adductor longus origin tear with hematoma formation, edema and distal retraction of the tendon (arrow). This is potentially disrupting the pre-pubic aponeurotic complex. (b) Axial fat saturated T2 MRI demonstrating a hematoma and retracted adductor longus tendon (arrow).

MR imaging reveals para-symphyseal hyperintensity on fluid-sensitive sequences, presumably reflecting edema due to increased stress response and areas of trabecular microtrauma [33]. Histological sampling of these T2 hyperintense para-symphseal regions has demonstrated new woven bone formation consistent with a bone stress response [34]. T1 weighted images can show widening of the symphyseal cleft in chronic cases. If stress fractures are also present these are often manifest as vertically oriented subchondral areas of $\mathrm{T} 1$ hypointensity adjacent to the pubic symphysis. 
(a)

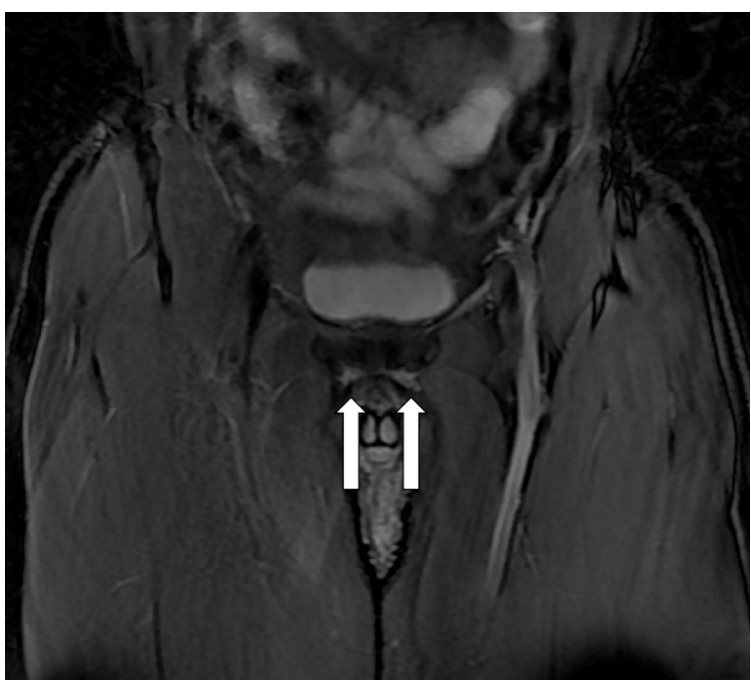

(c)

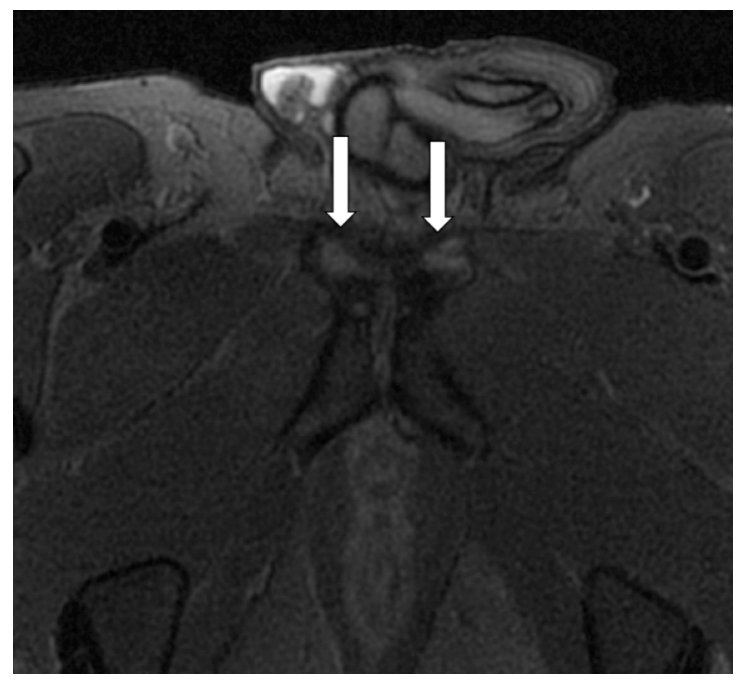

(e)

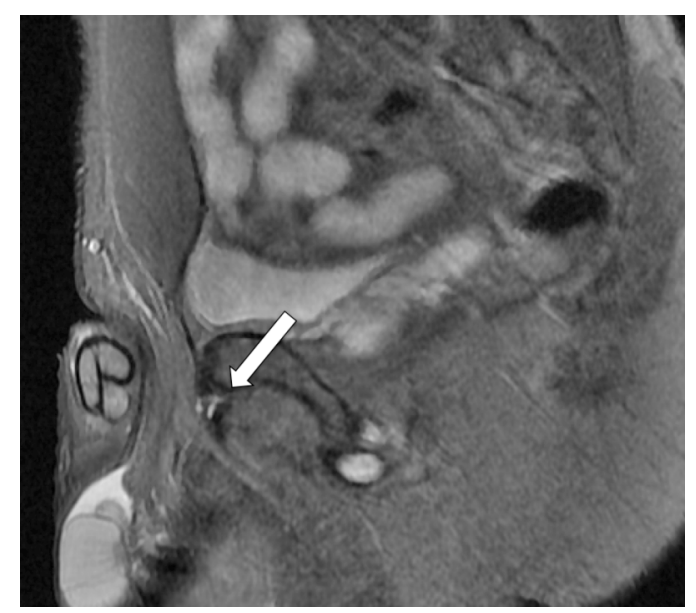

(b)

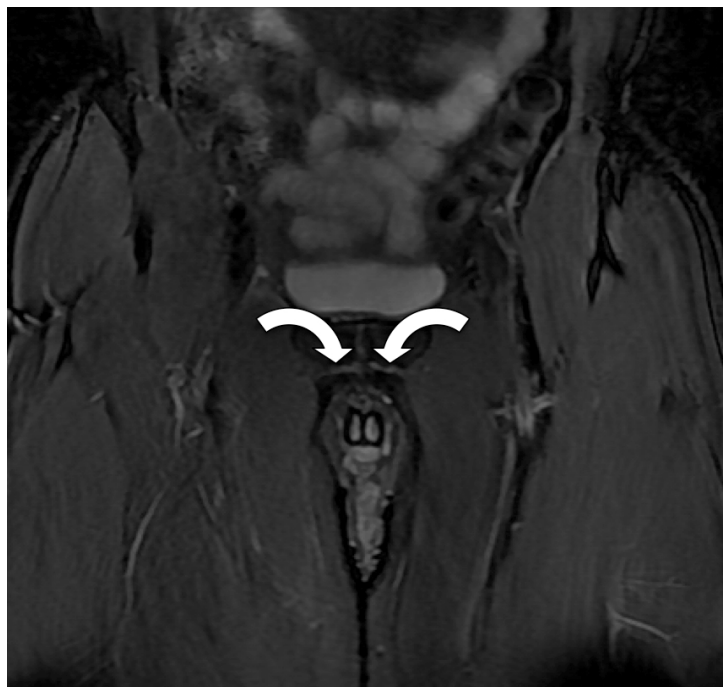

(d)

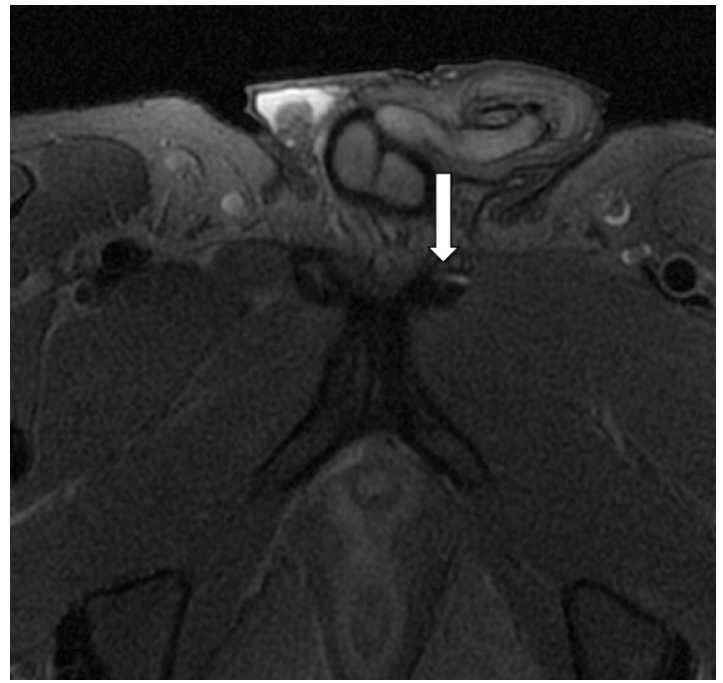

(f)

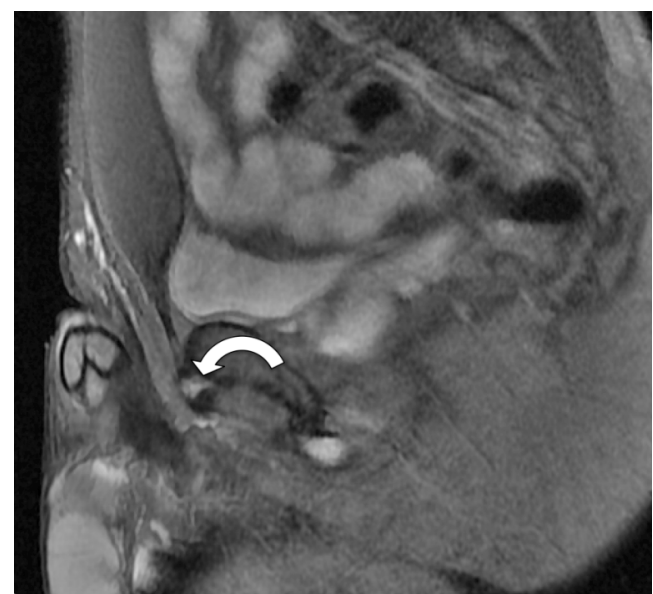

Fig. (2). (a) Coronal fat saturated T2 weighted MRI. Bilateral severe adductor longus origin tendinosis (arrows). (b) Coronal fat saturated T2 weighted MRI. Bilateral secondary clefts extending from the pubic symphysis into the adductor attachments indicating some disruption of the pre-pubic aponeurotic complex tissue (curved arrows). (c) Axial fat saturated T2 weighted MRI demonstrating bilateral adductor longus tendinosis (arrows). (d) 3D Axial fat saturated T2 weighted MRI. Small tear of the left adductor longus tendon (arrow). (e) Sagittal fat saturated T2 weighted MRI. Small tears of the origin of the left adductor longus tendon (arrow). (f) Sagittal fat saturated T2 weighted MRI. This demonstrates more severe adductor longus tendinosis that involves the pre-pubic aponeurotic complex (curved arrow). 
(a)

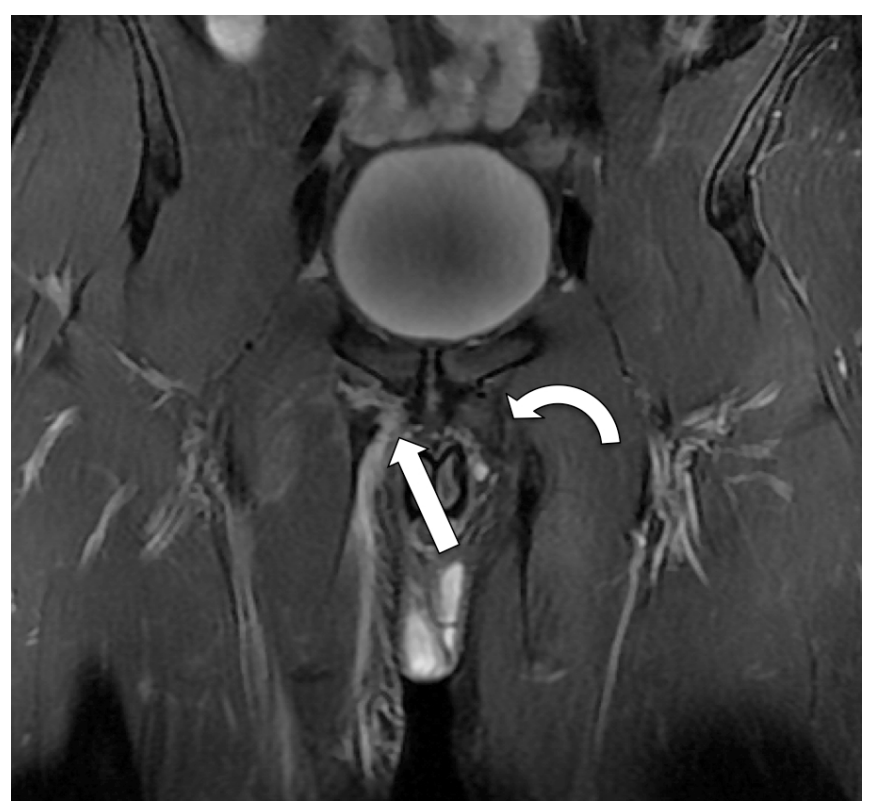

(b)

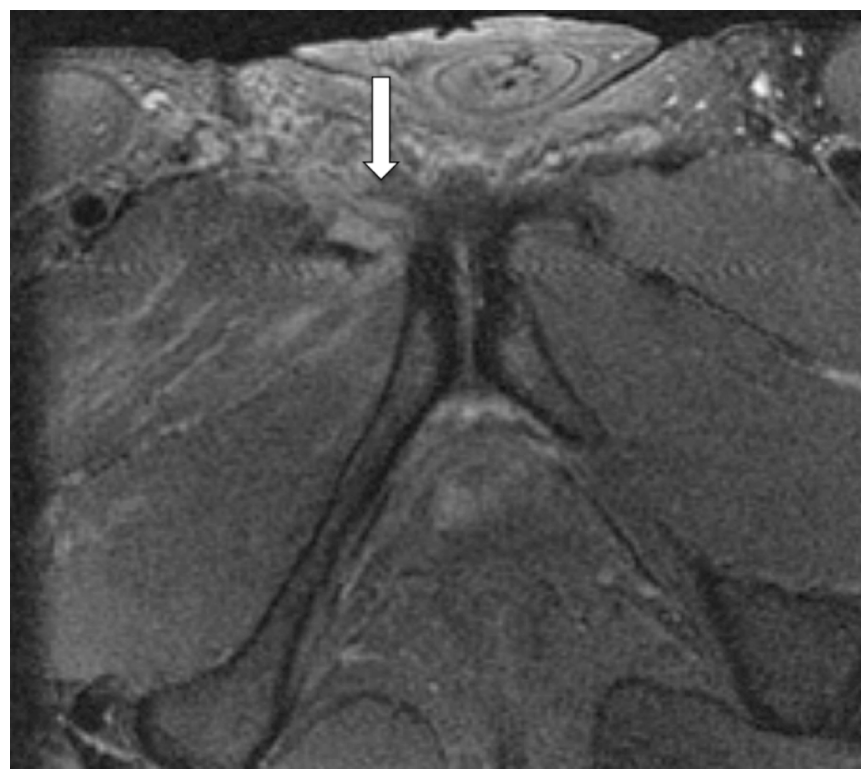

Fig. (3). (a) Coronal fat saturated T2 weighted MRI. Hyperintense signal abnormality at the origin of the right adductor longus tendon (straight arrow) consistent with an acute tear. Chronic tear of left adductor longus as evidenced by thickening and hypointensity with retraction of the tendon and healing with scar formation (curved arrow). (b) Axial fat saturated T2 weighted MRI image demonstrating acute right adductor longus tear (arrow).

\section{Sportsman's Hernia}

This condition has confusing clinical findings and historically varying terminology. It is interchangeably referred to as a sportman's hernia, pre-hernia complex, conjoint tendon tear, Gilmore groin, external oblique tear and inguinal wall deficiency $[4,17,25,30]$. The symptoms of a sportman's hernia can generally be described as pain referable to the medial inguinal area without evidence of a typical hernia on physical examination, usually experienced (a)

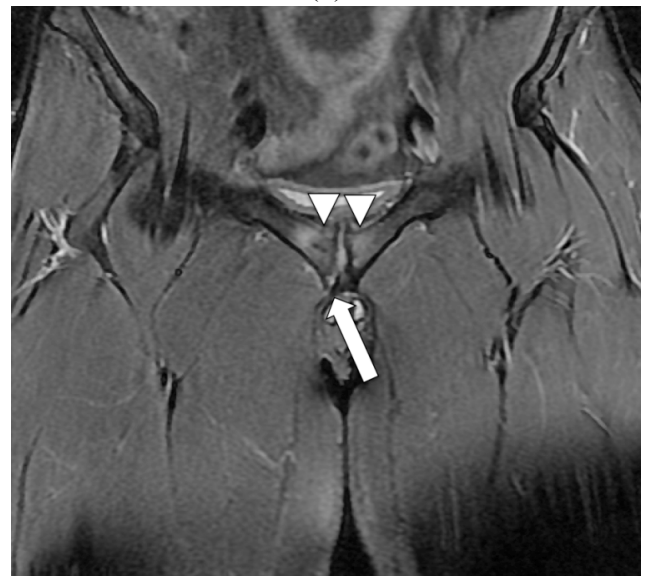

(b)

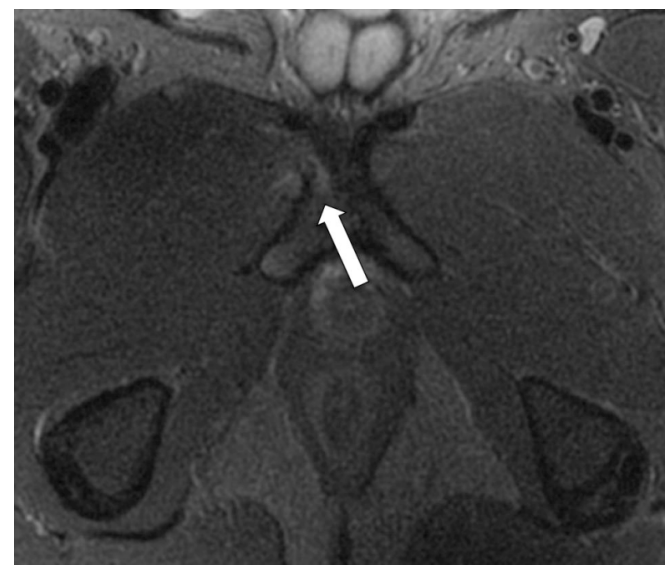

(c)

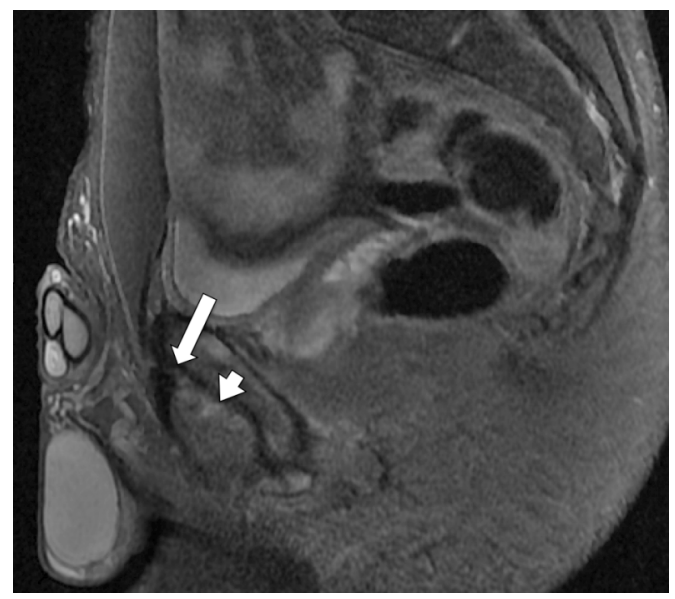

Fig. (4). (a) Coronal fat saturated T2 weighted MRI. Bilateral osteitis pubis, right worse than left, characterized by bone marrow hyperintensity (arrowheads), with microtearing along the medial right obturator externus attachment and disruption of the pre-pubic aponeurotic complex causing secondary cleft formation (straight arrow). (b) Axial fat saturated T2 weighted MRI demonstrating microtearing of the right obturator externus attachment posterior to adductor longus with secondary bony stress reaction (arrow). (c) Sagittal fat saturated T2 weighted MRI. Edema and microtearing of the origin of the obturator externus (short arrow) posterior to adductor longus and brevis extending posterior to the adductor longus origin from the pre-pubic aponeurotic complex (long arrow). 


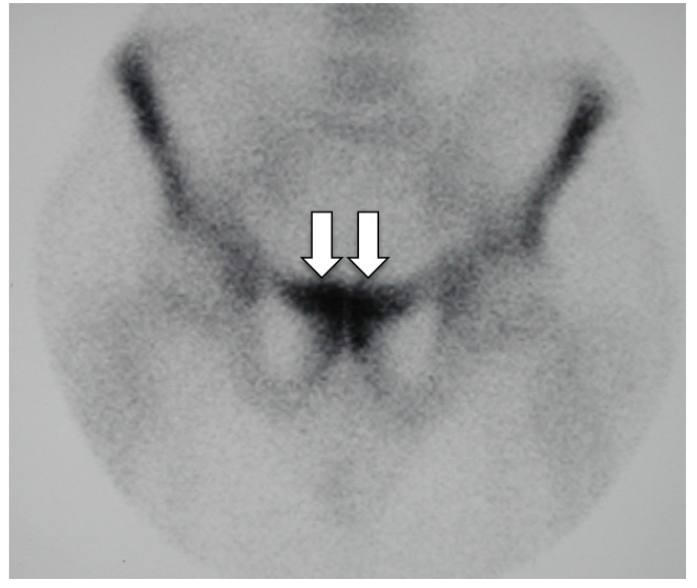

Fig. (5). Isotope bone scan shows concentration of radiotracer activity at the symphysis pubis in a patient with increased marginal osteoblastic activity in a 27 year old soccer player with osteitis pubis (arrows).

by athletes $[35,36]$. The pre-pubic aponeurotic complex is possibly a unifying structure to explain many presentations of this condition as it is a common anchor for the structures of the posteromedial inguinal canal (internal oblique and transversus abdominis via the rectus sheath); for the medial crus of the superficial inguinal ring; for the most medial aspect of the inguinal ligament itself and for the main stressors around the pubis (adductors and rectus abdominis). An adductor longus or rectus abdominis injury involving the aponeurotic complex may thus affect the structures of the inguinal canal. Depending on the anatomical component and the severity of the injury (from strain to tear), symptoms may range from mild tenderness without palpable protrusion of the inguinal wall, to severe tenderness and palpable protrusion with possible discrete hernia formation.

Gilmore's groin is classically described as tenderness over the superficial inguinal ring with evidence of dilation of the superficial inguinal ring on clinical examination [37]. The pathological process thus likely relates to the medial attachments of the external abdominis aponeurosis, which is a component of the pre-pubic aponeurosis. While the majority of patients cannot localize their symptoms precisely, approximately $40 \%$ of patients are found to have concomitant tenderness in the adductor region [38]. Another specific entity in the sportsman's hernia group is posterior inguinal wall deficiency, which has been attributed to an injury of the conjoint tendon. The classic description of the conjoint tendon is not a common finding at cadaveric dissection. The tendon actually merges with the anterolateral aspect of the rectus abdominis sheath as opposed to inserting onto the pubic crest [25]. This entity of posterior inguinal wall deficiency thus likely relates to an injury at the lateral attachment of the rectus abdominis, possibly secondary to disruption of the pre-pubic aponeurotic tissues, which weakens the internal oblique and transversus abdominis components of the inguinal canal. Incompetence of the posterior inguinal canal can be diagnosed with dynamic sonography by demonstrating anterior bulging of the posterior wall on straining [39].

The sportsman hernia is thus a nonspecific entity that can have variable symptoms and signs. MR imaging can reliably identify where an injury has occurred, the extent of that injury, and whether any other structures are involved. As groin injuries are commonly secondary to injury of the main muscular attachments at the pubis, it is important to note these injuries may variably extend to affect the medial inguinal canal components.

\section{Imaging of Hip Pain}

\section{Stress Response and Fractures}

Stress fractures occur when abnormal, repetitive stress is applied to normal bone. The repetitive stresses, none of which is singularly capable of producing fracture may lead to mechanical failure over time [40]. Stress fracture of the femoral neck typically occurs at the medial femoral neck in ballet dancers and long distance runners, with femoral shaft involvement seen in gymnasts (Fig. 6). Long distance runners may also display MR signal abnormalities including marrow edema, periostitis of the lesser trochanter in addition to bone marrow edema in the femoral neck [41]. The absence of a cortical fracture line on MR imaging allows differentiation of stress response from stress fracture (Fig. 7), which represent a spectrum of injury [42].

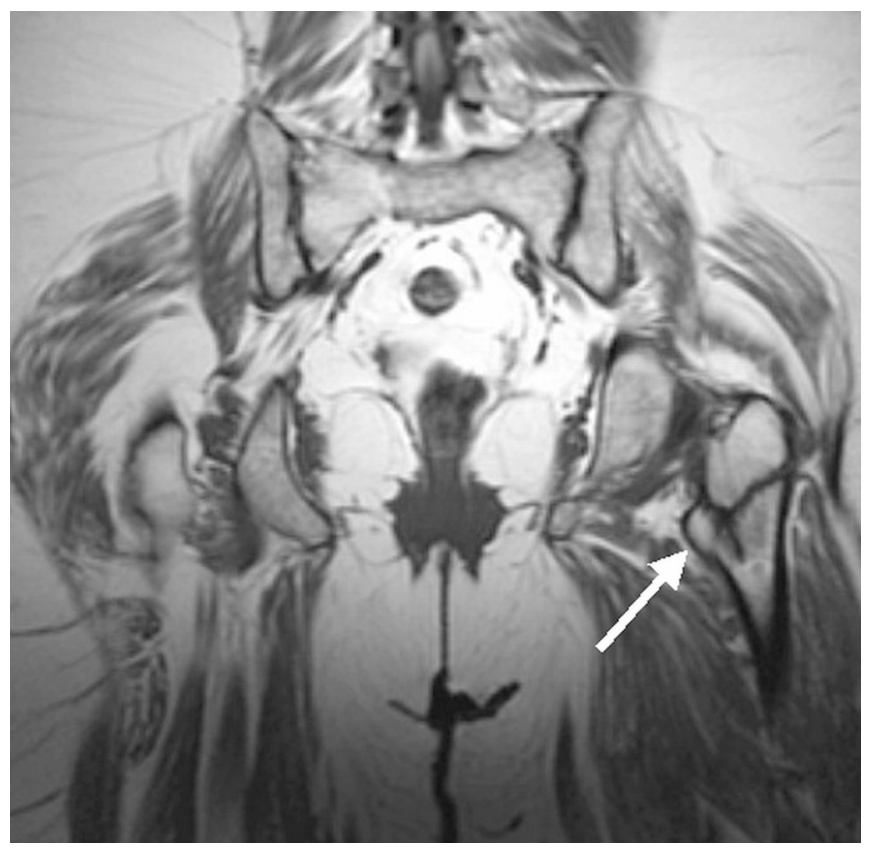

Fig. (6). T1 weighted coronal image demonstrating linear low signal intensity through the femoral neck (arrow) consistent with a complete stress fracture.

The radiographic features of stress fracture vary in accordance with the location and chronicity of injury and may include periosteal reaction, endosteal sclerosis, cortical thickening and a lucent fracture line [41]. Radiographs are often unrevealing with follow up films demonstrating abnormalities in only $50 \%$ while bone scintigraphy may result in a false positive diagnosis in up to $30 \%$ of cases $[16$, 43]. Bone scintigraphy has therefore been largely superseded by MRI as the imaging modality of choice due to its superior spatial resolution [44]. Edematous marrow has low signal intensity on T1 weighted images and markedly high signal intensity on $\mathrm{T} 2$ weighted fat suppressed or short tau inversion recovery (STIR) images. Edematous marrow, 


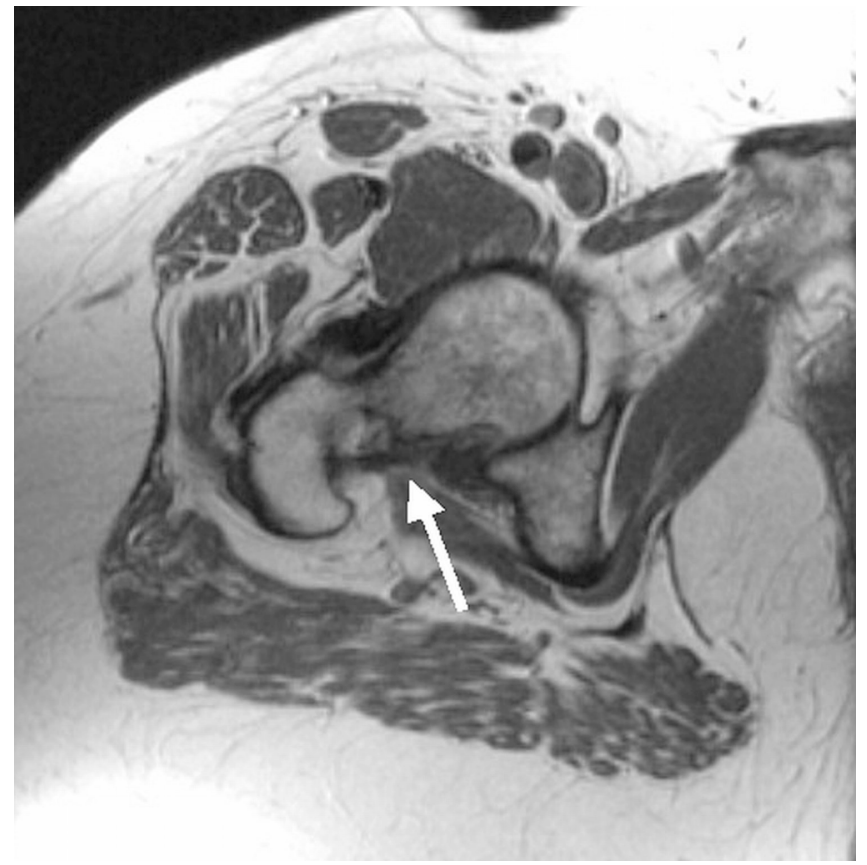

Fig. (7). T1 weighted axial image showing incomplete stress fracture (arrowhead) through the femoral neck. Note the adjacent edematous marrow (arrow) in the femoral neck manifest as low signal intensity change.

unlike reconversion marrow, is much more intense on STIR images and does not respect boundaries such as the physis (Fig. 8).

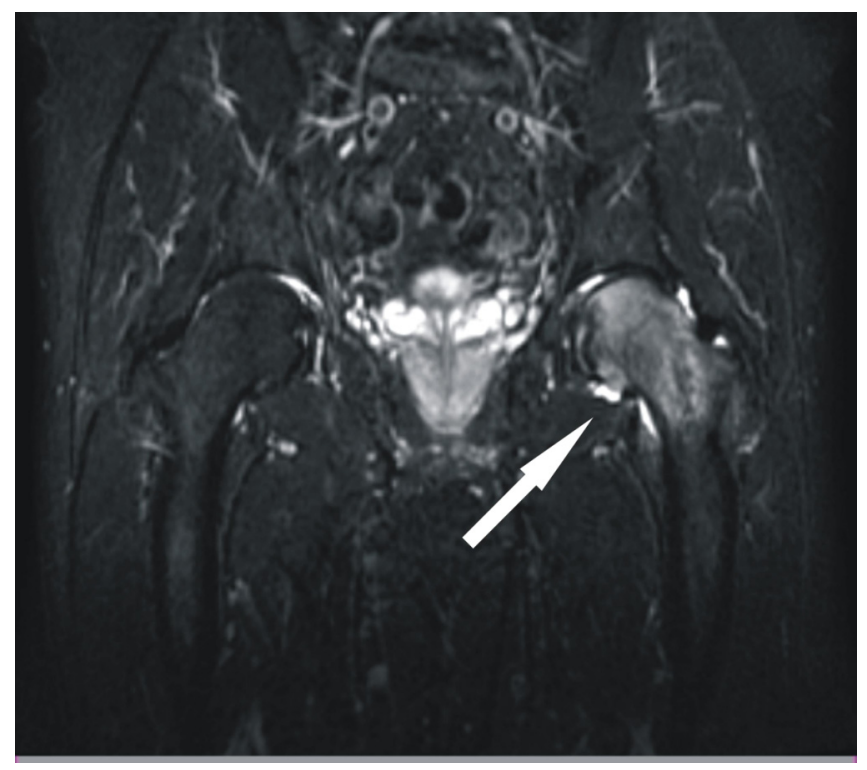

Fig. (8). T2 STIR weighted coronal image showing florid marrow edema (arrow) within the femoral head and neck with incomplete femoral neck stress fracture. Associated joint effusion.

MRI findings of periosteal and marrow edema are early signs of stress response with low signal intensity most conspicuous on T1 weighted sequences confirming discrete stress fracture formation [45]. Stress fractures displaying fragmentation and osteolysis with low signal intensity on T2 weighted sequences are suggestive of more long standing injury.
MRI is of greater usefulness in the follow up imaging of patients with stress fractures. Non-displaced femoral stress fractures usually show resolution of T2 and STIR high signal intensity within six months of the first MR study [46, 47].

\section{Apophyseal Injuries}

Apophysitis represents the earliest spectrum of injury to the apophysis with excessive stress the underlying cause. It is most prevalent in the skeletally immature patient, occurring in patients between the ages of 12 and 22 years of age athletes clinically presenting with athletic pubalgia [16].

Apophysitis in the pelvis may involve the anterior superior iliac spine (sartorius and tensor fascia lata muscles) (Fig. 9), the anterior inferior iliac spine (rectus femoris) and the ischial tuberosity (semitendinosus, semimembranosus, long head of biceps and ischial origin of adductor magnus). Fluid sensitive sequences reveal marrow edema in the apophysis with associated high signal intensity consistent with edema in the involved muscle and associated peritendinous edema (Fig. 10). Increased signal intensity on fluid sensitive sequences and mild widening of the physis, often with adjacent bone marrow edema are characteristic of apophysitis in adolescent athletes. If these overuse injuries are not recognized, particularly in athletes involved in kicking of sports, avulsive injuries may occur. When there is no history of a specific traumatic event and plain film findings are confusing, MRI can be crucial in avoiding unnecessary imaging and potential biopsy, as well as excluding high-grade tendon injury. Posttraumatic appearance at the site of avulsive injury may simulate osteomyelitis or malignancy.

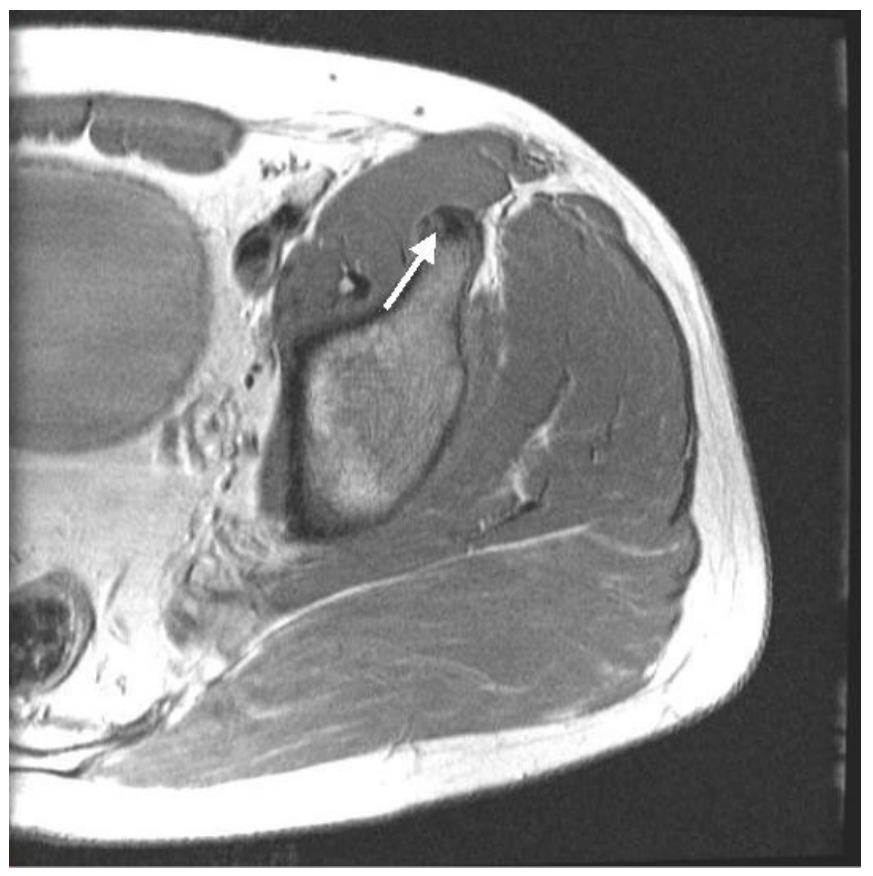

Fig. (9). T1 weighted axial image demonstrating anterior iliac spine apophysitis (arrow).

Avulsion injuries primarily occur at six sites in the pelvis; the iliac crest, anterior superior iliac spine, anterior inferior iliac spine (Fig. 11), greater trochanter, lesser trochanter, body of pubis and ischial tuberosity [48, 49]. On 


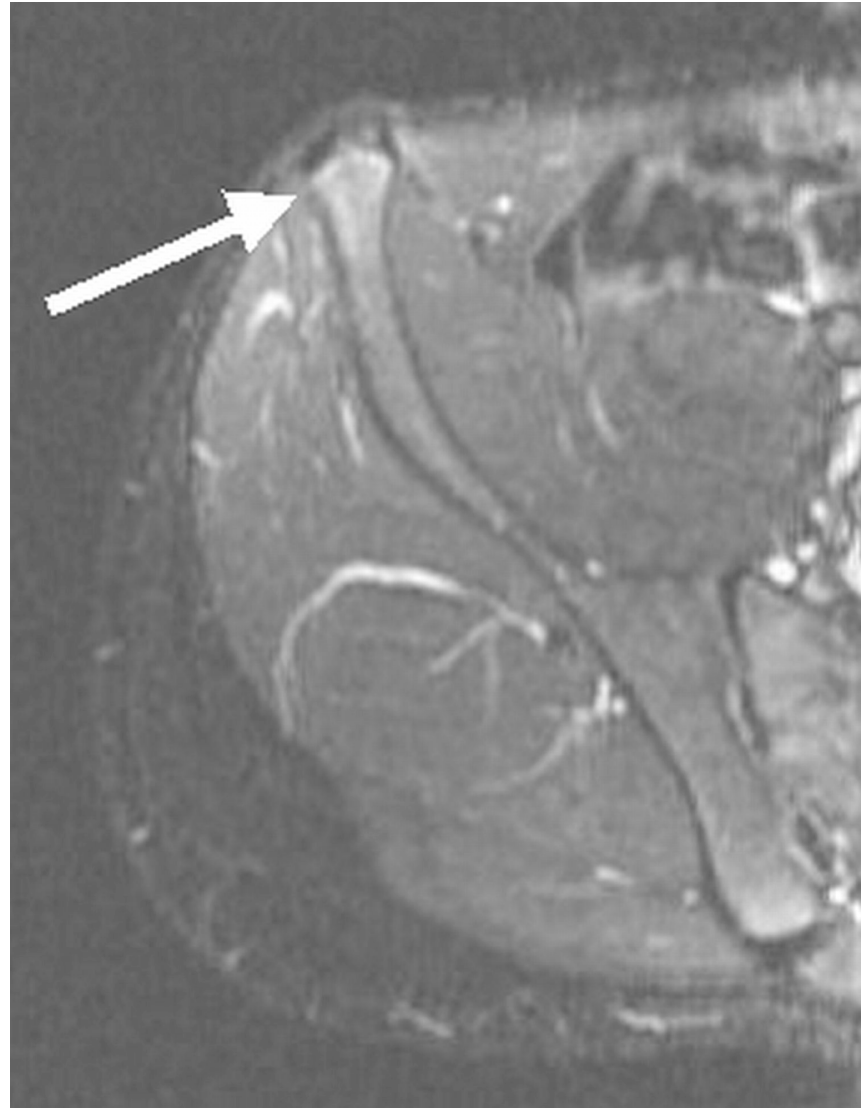

Fig. (10). T2 STIR weighted axial image of pelvis showing edema (arrow) of the anterior superior iliac spine with irregularity typical of apophysitis.

plain film assessment, acute injuries are associated with avulsed bone fragments while injuries that are more chronic may have an aggressive appearance of mixed sclerosis and lysis. Coronal fluid sensitive images are particularly useful in assessing the pelvis with marrow edema and reactive change in the surrounding in the surrounding soft tissues at the site of repetitive microtrauma. Often MR images will show irregularity and bony protuberance at the avulsive site with the displaced bone fragment visible. Fortunately, the periosteum and surrounding fascia often limits severe displacement (Fig. 12). In non-displaced avulsions, sharply marginated pieces of bone are seen adjacent to its donor site.

\section{Snapping Hip Syndrome}

Snapping hip syndrome (coxa saltans, iliopsoas tendonitis, or dancer's hip) is a clinical entity referring to an audible snap or click occurring at the hip joint commonly seen in athletes including distance track and field runners, ballet dancers, gymnasts, horse riders and soccer players where repetitive hip flexion leads to injury. A number of different etiologies, both intra-articular and extra-articular have been described. Taking into account the localization of the causes for snapping hip, three different syndromes are described.

Lateral (external) extra-articular type of snapping hip syndrome occurs when movement of the iliotibial band, tensor fascia lata or gluteus medius is partially obstructed when sliding over the greater trochanter. The medial (internal) extra-articular type involves the iliopsoas tendon, as it moves from an anterolateral to a posteromedial position. The iliopsoas tendon comes into contact with an osseous protuberance most commonly the iliopectineal eminence or a prominent anterior-inferior iliac spinal process during hip extension [50].

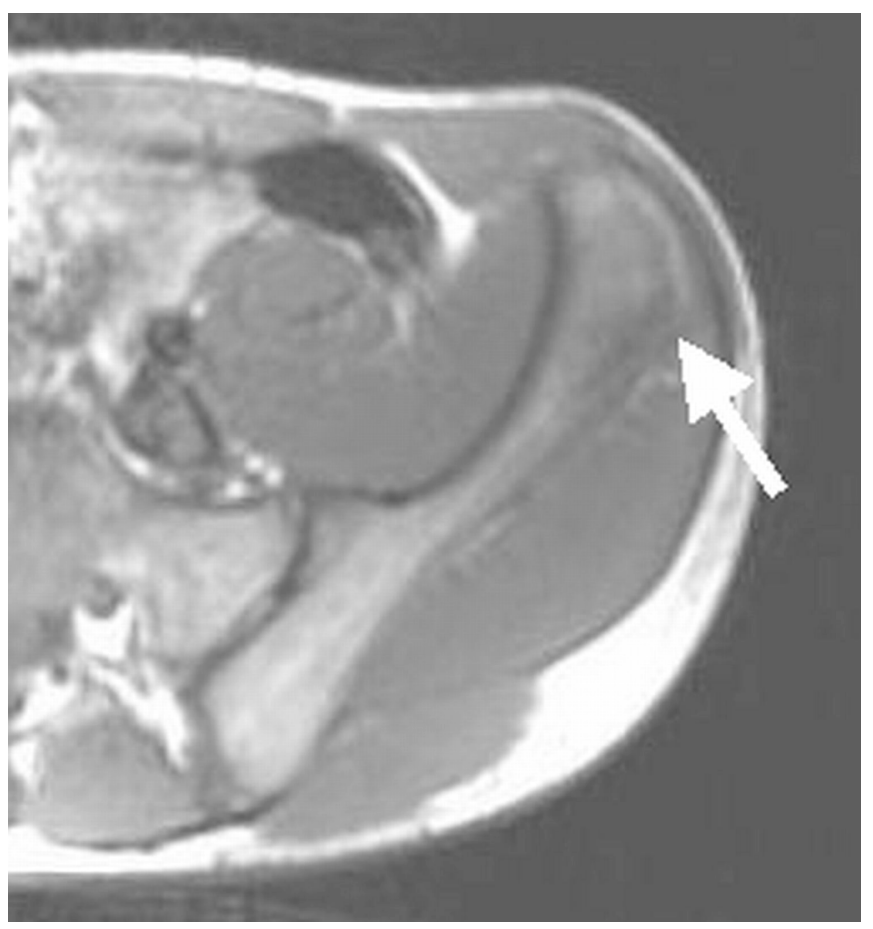

Fig. (11). T1 weighted axial image showing apophysitis of the anterior superior iliac spine and marrow edema (arrow) manifest as low signal intensity.

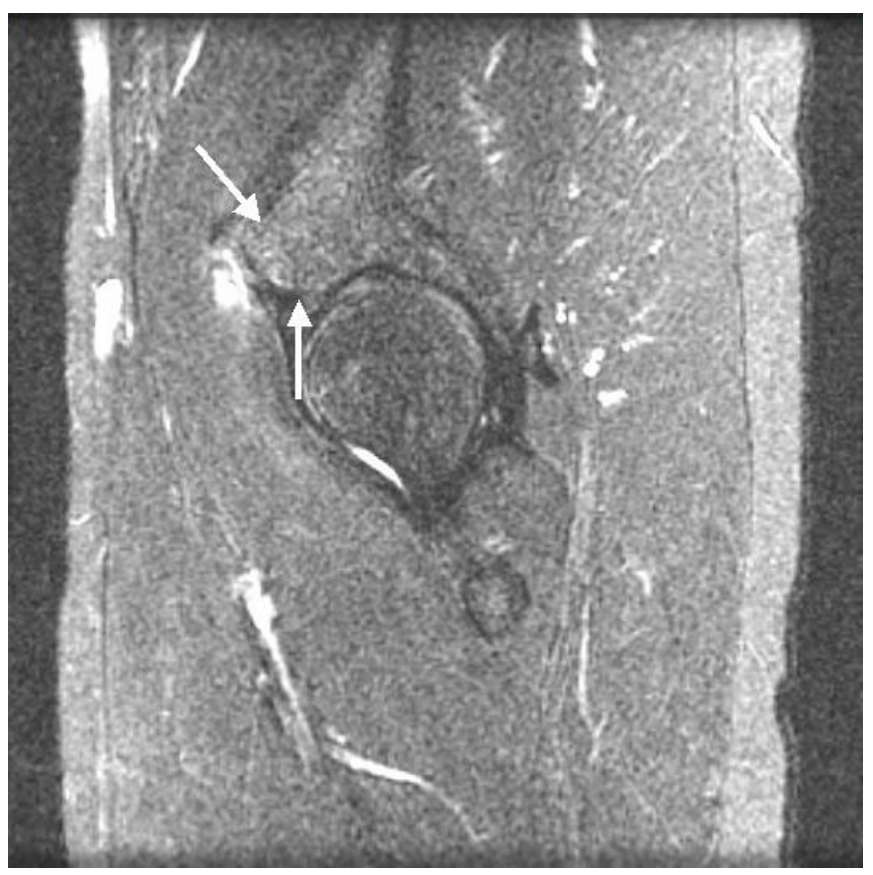

Fig. (12). T2 STIR weighted sagittal image showing minimally displaced bone fragment (arrows) arising from the anterior inferior iliac spine with MR features consistent with acute avulsive injury. Associated reactive changes in adjacent soft tissues.

Intra-articular snapping hip syndrome is often indicative of a torn acetabular labrum, recurrent hip dislocation, 
ligamentum teres tears, loose bodies or articular cartilage damage.

With chronic repetitive movement, affected patients will develop iliopsoas tendon pathology such as iliopsoas bursitis and tendinosis. Classically when a snapping iliopsoas tendon was suspected, bursography or tenography procedures were used preoperatively to confirm the diagnosis. Ultrasound allows for dynamic visualization of the iliopsoas tendon as it passes over the iliopectineal eminence during dynamic maneuvers as well as detecting bursitis [51]. MR allows for more thorough assessment of patients with snapping hip syndrome than ultrasound, allowing evaluation of potential intra-articular causes of snapping hip syndrome. The diagnosis should be considered when thickening of the iliopsoas tendon in association with altered intrasubstance signal intensity is identified next to an osseous spur arising from the iliopectineal eminence.

Lateral (external) snapping hip syndrome is the most frequent snapping hip syndrome [52]. It is caused most commonly by the iliotibial band as it slides over the greater trochanter and is frequent in runners, dancers and basketball players. Ultrasound demonstrates the abnormal motion of the iliotibial band or gluteus maximus tendon but is highly user dependent. MRI may demonstrate a number of findings in patients with external snapping hip syndrome. In cases with iliotibial band involvement, fluid may be found in the trochanteric bursa and is most easily identified on T2 weighted images [53]. In cases with iliopsoas tendon involvement, the tendon may be thicker relative to the contralateral side, most obvious on coronal pelvic images. Additional MRI findings commonly seen include changes consistent with iliopsoas tendonitis, tendinosis or both. Tendinosis is demonstrated on spin- echo T1 weighted images as an area of higher signal intensity within the tendon with less marked signal change on T1 weighted images. In cases of tendonitis, increased fluid in the iliopsoas peritendinous tissues is conspicuous on spin-echo T2 weighted images or STIR sequences as a focus of high signal intensity surrounding a normal tendon [52,53].

\section{Greater Trochanteric Pain Syndrome}

Lateral hip pain is often a challenging diagnostic problem with a wide range of diagnostic considerations that may present in a similar fashion. Many pathological processes such as trochanteric bursitis, tendinosis and tears of the gluteal medius and minimus muscles, degenerative hip arthropathy, stress fractures and entrapment syndromes may all present with similar symptoms. This encompasses not only trochanteric bursitis but also what have been labelled rotator cuff tears of the hip, analogous to rotator cuff tears in the shoulder [54]. The term "rotator cuff tear" refers to a tear in one or more tendons of the hip abductors. Typically, this is a circular or oval defect in the gluteus minimus tendon extending posteriorly into lateral part of gluteus medius with signs of trochanteric bursitis and gluteal tendon tears frequently co-existing on MR imaging and surgical correlation.

The greater trochanteric pain syndrome is a common regional pain syndrome most often clinically diagnosed as trochanteric bursitis and typically presents with pain along the lateral hip aspect [54]. The trochanteric bursal complex comprises the major bursae, subgluteus maximus and medius bursae and the solitary minor bursa, subgluteus minimus [55]. Studies examining the trochanteric bursal complex and our understanding of the greater trochanteric bursitis, reveals that tendinopathy of the gluteus medius and minimus muscles in these patients forms part of a spectrum of injury, commencing with bursitis secondary to impingement followed by tendinopathy and the formation of tears [56, 57].

Trochanteric bursitis is described if distension of the subgluteus maximus or medius bursa is evident on T1 or T2 weighted images. This MR finding is quite commonly absent and likely explains why the term greater trochanter pain syndrome rather than trochanteric bursitis is increasingly employed. Trochanteric bursitis has been demonstrated to co-exist with gluteal tendinosis in up to $40 \%$ of patients with bursitis and manifests as homogeneous T2 hyperintensity, which may display enhancement post contrast administration on MR imaging. Gluteal tears typically appear as a circular or oval defect most commonly in the gluteus minimus tendon commonly extending into the lateral part of the gluteus medius tendon [58]. A partial tear is diagnosed where focal tendon discontinuity is present and complete tear when full thickness abnormality or tendon retraction is evident. The term "bald trochanter" is used when there are full thickness tears of both gluteus medius and minimus with retraction evident on MR [59]. Partial tears may occur in isolation but often occur on a background of underlying gluteal tendinosis or tendinopathy [54]. Gluteal tendinopathy on MR imaging manifests as thickening of the tendon and T2 weighted signal intermediate to high signal intensity (Fig. 13).

\section{Iliopsoas Bursitis and Tendinosis}

The iliopsoas musculotendinous unit is becoming recognized as an important cause for hip pain in the general and athletic population with iliopsoas tendinosis, snapping hip syndrome, iliopsoas bursitis and avulsion injuries all recognized entities [60]. The iliopsoas tendon inserts on the lesser trochanter allowing hip flexion and external rotation of the femur. The iliopsoas bursa is found in $98 \%$ of subjects, communicates with the cavity of the hip in about $15 \%$ of cases, and is readily demonstrated on hip arthrography?

The normal iliopsoas bursa separates the iliopsoas tendon from the hip joint articular capsule and is collapsed on MR imaging. The distension present within the iliopsoas bursa on MR imaging is variable and characteristically extends along the iliopsoas muscle. Imaging characteristics of iliopsoas bursitis are a well-defined, cystic mass posterior to the iliopsoas tendon. The signal characteristics of the fluid within the bursa are typically similar to water and thus homogeneously hyperintense on fluid sensitive sequences but may appear heterogeneous if loose bodies or PVNS is present. In most cases the bursal wall displays peripheral contrast enhancement [61]. Concurrent hip effusion is often seen in patients with iliopsoas bursitis with bursal distension caused by overproduction of synovial fluid within an arthritic hip decompressing into the bursa (Fig. 14). The iliopsoas tendon should appear uniformly low signal intensity on $\mathrm{T} 1$ and $\mathrm{T} 2$ weighted images. MR imaging in iliopsoas tendinosis shows focal high signal intensity on the 
(a)

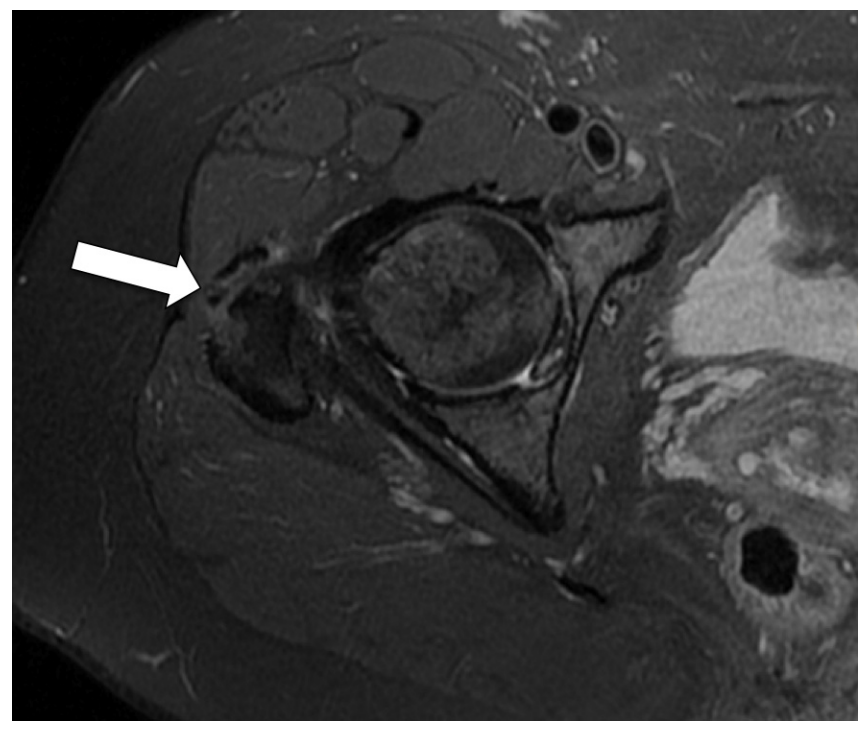

(b)

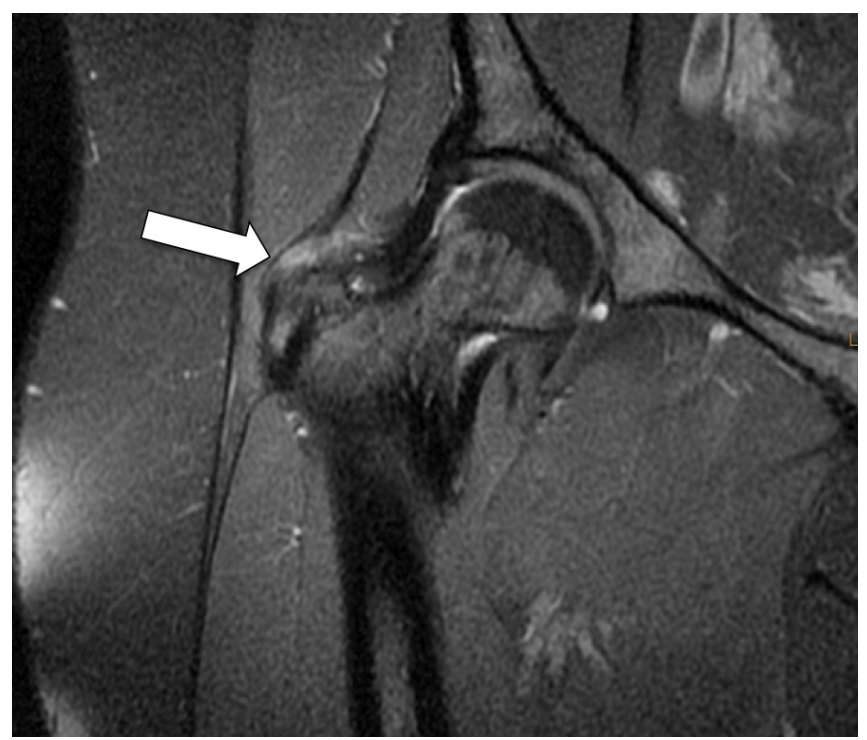

Fig. (13). (a) Axial fat saturated T2 weighted image demonstrating gluteus minimus tendinosis at its insertion on the anterior border of the greater trochanter (arrow). (b) Coronal fat saturated T2 weighted image in same patient demonstrating the abnormal high signal of gluteus minimus tendinosis.

spin-echo T1 weighted within the iliopsoas tendon with less marked abnormality on spin-echo T2 weighted images. The use of MR imaging also allows exclusion of acute musculotendinous injury which displays conspicuous T2 increased signal intensity associated with inflammation and swelling. However, in instances of more severe injury, both the T1 weighted images and T2 weighted images depict high signal change $[62,63]$.

\section{Labrum and Hip Joint Capsule}

Radiographs are typically normal in patients with internal derangement as a cause for hip pain. Labral lesions have a strong correlation with anterior hip pain, transient locking and subluxation of the hip with pain reproduced with internal rotation and flexion of the hip with an audible click occasionally heard [64].

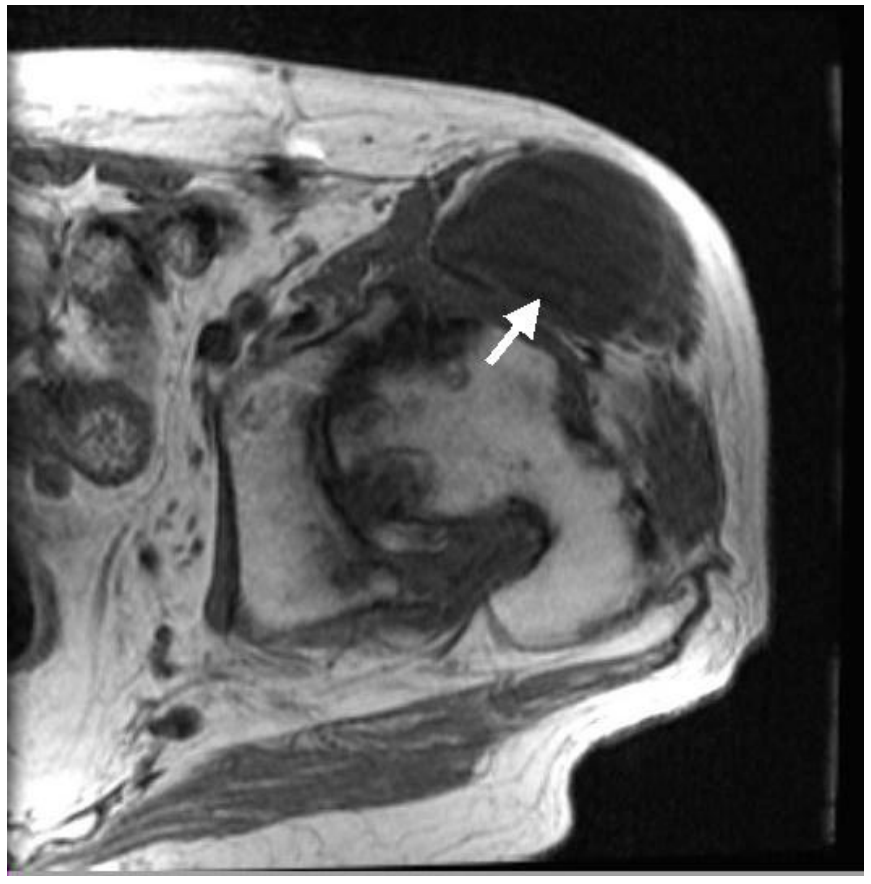

Fig. (14). T1 weighted axial image with features of erosive hip arthropathy with hip joint effusion and associated (arrow) iliopsoas bursitis.

MR arthrography has emerged as the gold standard for the preoperative diagnosis of labral tears. In addition to identifying labral lesions, previously usually visible only at arthroscopy, loose bodies and other intra-articular causes for hip pain are demonstrated. Once intra-articular needle placement has been confirmed in the fluoroscopy suite, a dilute solution $(0.2 \mathrm{mmol} / \mathrm{L})$ of gadopentetate dimeglumine is injected. The high signal intra-articular gadopentetate solution is most conspicuous on T1 weighted imaging with fat saturation routinely employed to increase contrast. Images are obtained in the three orthogonal planes given the spherical nature of the hip joint with the normal labrum uniformly low signal intensity on $\mathrm{T} 1$ weighted images with internal intermediate signal intensity at the junction of the articular cartilage and labrum [65]. Both acetabular and glenoid labral tears share common features on MR arthrography. Labral tears in both instances begin at the junction of labral fibrocartilage and hyaline cartilage and may extend into the labral substance or extend to the bony labral attachment [66]. Detachments occur more frequently than tears and are visible as contrast material interposed at the acetabular-labral junction. Sports related labral tears occur anterosuperior on the acetabular rim (Fig. 15), visible as a labral detachment separating the base of the labrum from underlying bone $[64,65]$. In cases of hip dysplasia, labral tears are identified superior (lateral) on the acetabular rim secondary to repeated femoral head impaction [67]. Paralabral cysts may develop adjacent to labral tears with extrusion of fluid into the periarticular soft tissues and should provoke careful search for a labral tear (Fig. 16) with other ancillary findings including subchondral marrow edema and subchondral cystic change. In most cases, gadolinium injected at arthrography fails to fill these cysts. As a torn labral fragment becomes detached from the acetabular rim, its protection of adjacent articular cartilage 
decreases and weight-bearing forces become unevenly distributed over the cartilaginous surface.

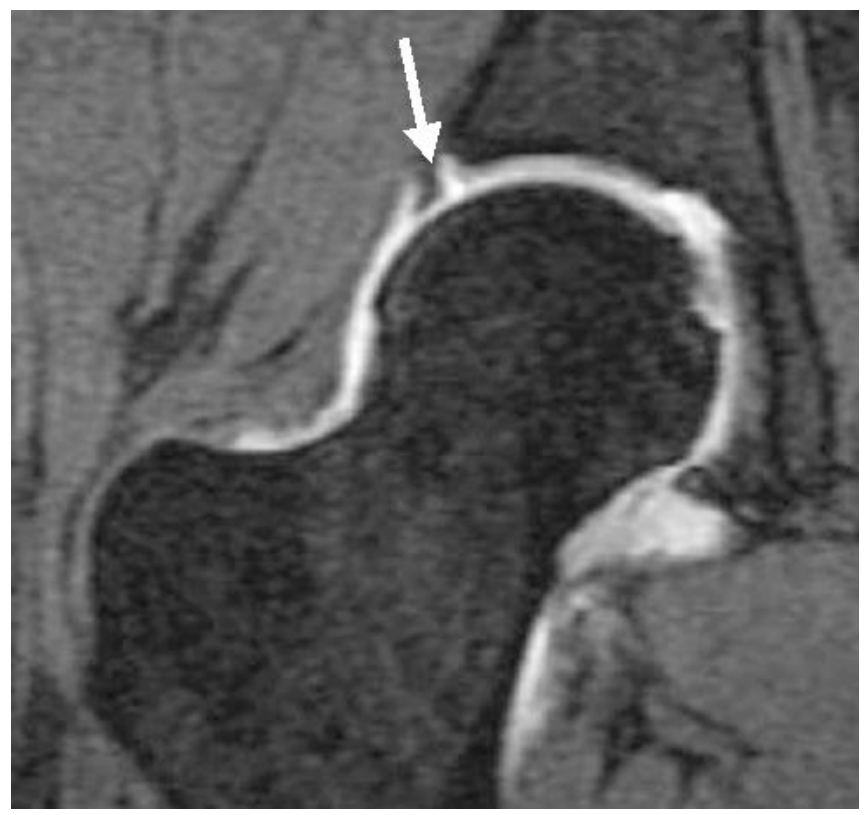

Fig. (15). Coronal T1 fat suppressed direct hip arthrogram showing an anterosuperior labral tear (arrow).

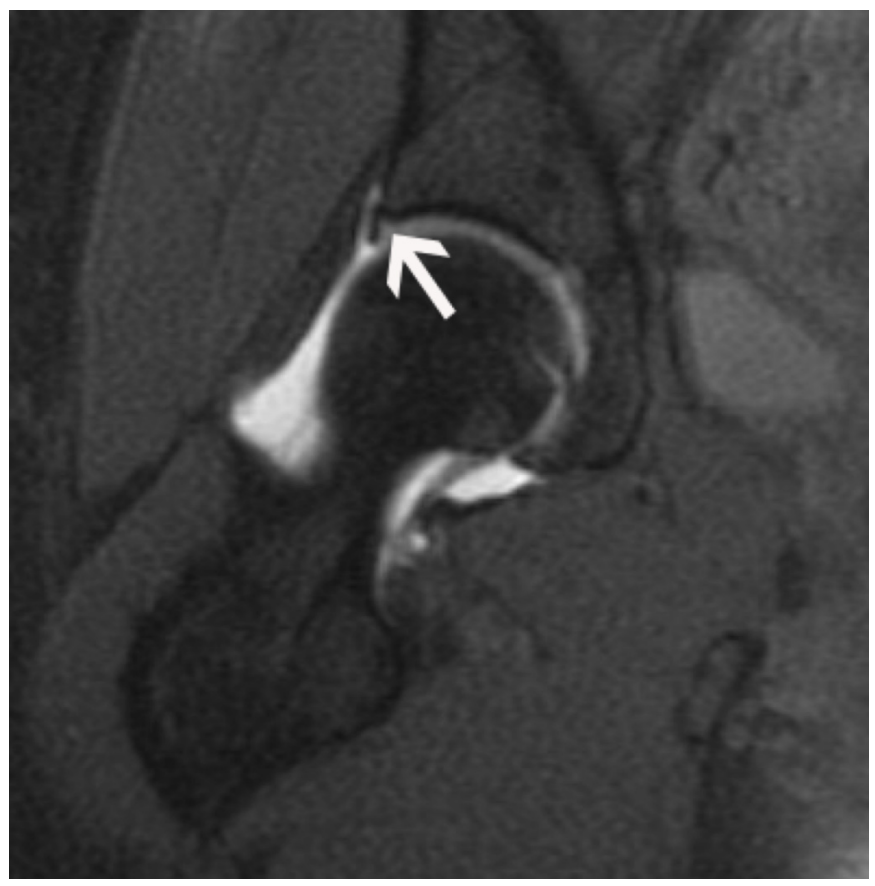

Fig. (16). Direct MRA of the right hip in a 24 year old gymnast with hip pain. This coronal image shows direct contrast imbibement (arrow), into a surgically confirmed hip labral tear.

Femoroacetabular impingent (FAI) occurs when there is an abnormal configuration between the acetabular rim and proximal femur. It is classified into cam FAI and pincer FAI depending on the presence of either a femoral or an acetabular abnormality respectively. In cases of cam type impingement, the non-spherical shape of the femoral head at the femoral head-neck junction and reduced depth of the femoral waist leads to abutment of femoral head neck junction against the acetabular rim [64]. With cam impingement, articular cartilage injury and labral tears usually occur along the anterior and superolateral acetabular rim. In pincer type impingement, over coverage of the acetabulum as in protrusio acetabuli or localized in patients with acetabular retroversion is the underlying cause. Pincer type impingement results in more severe cartilage damage at the posterior and posteroinferior acetabulum. In both types of impingement, labral and bony acetabular changes frequently coincide, with an osseous deformity visible at the femoral head-neck junction [67]. The majority of patients with proven labral tears have an abnormality on hip radiograph [68]. The irregular ossification and osteophyte formation of the acetabular rim leads to progressive over coverage of the femoral head and exacerbates the FAI. Frequently, an os-acetabuli, which initially develops at eight years of age before uniting with the os-pubis in late adolescence, is identified on MR in patients with FAI and is secondary to abnormal stresses causing fragmentation of the bony fragment [69-71]. In patients with advanced cartilage delamination, joint preserving surgery may no longer be possible and therefore accurate assessment is vital. Unfortunately, the diagnosis of cartilage delamination is difficult even with MR arthrography. The difficulty arises in diagnosis because in delamination the cartilage surface may be intact but the cartilage layer moves relative to the underlying bone plate [60]. Overall the sensitivity of MR arthrography for assessment of the acetabular cartilage in FAI ranges from $65 \%-100 \%$ with specificity falling to $40 \%$ $80 \%$ [72]. Initial reports on delamination described the "inverted Oreo cookie" sign, where the cartilage flap appears as a linear articular low signal filling defect surrounded by intra-articular contrast material [73]. This is infrequently found however, with hypointensity of the articular cartilage on intermediate- weighted fat- saturated, and T1 weighted images a more helpful finding in the diagnosis of cartilage delamination $[73,74]$.

\section{CONCLUSION}

Patients with groin and hip pain have diverse causes for presentation. Modern high field MR imaging is an excellent diagnostic modality for the assessment of groin and hip pathology. Familiarity with the complex anatomy and typical MR findings associated with overuse injuries of these regions facilitates an accurate and timely diagnosis.

\section{REFERENCES}

[1] DeLee JC, Farney WC. Incidence of injury in Texas high school football. Am J Sports Med 1992; 20: 575-80.

[2] Gomez E, DeLee JC, Farney WC. Incidence of injury in Texas girls' high school basketball. Am J Sports Med 1996; 24: 684-7.

[3] Crowninshield RD, Johnston RC, Andrews JG, Brand RA. A biomechanical investigation of the human hip. J Biomech 1978; 11 75-85.

[4] Kavanagh EC, Koulouris G, Ford S, McMahon P, Johnson C, Eustace SJ. MR imaging of groin pain in the athlete. Semin Musculoskelet Radiol 2006;10:197-207.

[5] Gilmore J. Groin pain in the soccer athlete: fact, fiction, and treatment. Clin Sports Med 1998;17: 787-93, vii.

[6] Syme G, Wilson J, Mackenzie K, Macleod D. Groin pain in athletes. Lancet 1999; 353: 1444.

[7] Karlsson J, Sward L, Kalebo P, Thomee R. Chronic groin injuries in athletes. Recommendations for treatment and rehabilitation. Sports Med 1994; 17: 141-8.

[8] Fricker PA. Management of groin pain in athletes. Br J Sports Med 1997; 31: 97-101.

[9] Renstrom P, Peterson L. Groin injuries in athletes. Br J Sports Med 1980;14: 30-6. 
[10] Lynch SA, Renstrom PA. Groin injuries in sport: treatment strategies. Sports Med 1999; 28: 137-44.

[11] Holmich P, Uhrskou P, Ulnits L, et al. Effectiveness of active physical training as treatment for long-standing adductor-related groin pain in athletes: randomised trial. Lancet 1999; 353: 439-43.

[12] Ahumada LA, Ashruf S, Espinosa-de-los-Monteros A, et al. Athletic pubalgia: definition and surgical treatment. Ann Plast Surg 2005; 55: 393-6.

[13] Albers SL, Spritzer CE, Garrett WE, Jr., Meyers WC. MR findings in athletes with pubalgia. Skeletal Radiol 2001; 30: 270-7.

[14] Morelli V, Weaver V. Groin injuries and groin pain in athletes: part 1. Prim Care 2005; 32: 163-83.

[15] Slavotinek JP, Verrall GM, Fon GT, Sage MR. Groin pain in footballers: the association between preseason clinical and pubic bone magnetic resonance imaging findings and athlete outcome. Am J Sports Med 2005; 33: 894-9.

[16] Omar IM, Zoga AC, Kavanagh EC, et al. Athletic pubalgia and "sports hernia": optimal MR imaging technique and findings. Radiographics 2008; 28: 1415-38.

[17] Koulouris G. Imaging review of groin pain in elite athletes: an anatomic approach to imaging findings. AJR Am J Roentgenol 2008;191: 962-72.

[18] Robinson P, Salehi F, Grainger A, et al. Cadaveric and MRI study of the musculotendinous contributions to the capsule of the symphysis pubis. AJR Am J Roentgenol 2007;188: W440-5.

[19] Tuite DJ, Finegan PJ, Saliaris AP, Renstrom PA, Donne B, O'Brien M. Anatomy of the proximal musculotendinous junction of the adductor longus muscle. Knee Surg Sports Traumatol Arthrosc 1998; 6: 134-7.

[20] Gibbon WW, Schilders E. Pelvis, Hip and Groin. In: Vanhoenacker F, Maas M, Gielen J, Eds. Imaging of Orthopedic Sports Injuries. Berlin-Heidelberg: Springer 2007; pp. 235-65.

[21] Budinoff LC, Tague RG. Anatomical and developmental bases for the ventral arc of the human pubis. Am J Phys Anthropol 1990; 82: 73-9.

[22] Czerny C, Hofmann S, Neuhold A, et al. Lesions of the acetabular labrum: accuracy of MR imaging and MR arthrography in detection and staging. Radiology 1996; 200: 225-30.

[23] Keene GS, Villar RN. Arthroscopic anatomy of the hip: an in vivo study. Arthroscopy 1994;10: 392-9.

[24] Cunningham PM, Brennan D, O'Connell M, MacMahon P, O'Neill $P$, Eustace S. Patterns of bone and soft-tissue injury at the symphysis pubis in soccer players: observations at MRI. AJR Am J Roentgenol 2007; 188: W291-6.

[25] Zoga AC, Kavanagh EC, Omar IM, et al. Athletic pubalgia and the "sports hernia": MR imaging findings. Radiology 2008; 247: 797807.

[26] Gibbon WW. Groin pain in athletes. Lancet 1999; 353: 1444-5.

[27] Walheim GG, Selvik G. Mobility of the pubic symphysis. In vivo measurements with an electromechanic method and a roentgen stereophotogrammetric method. Clin Orthop Relat Res 1984:12935.

[28] Maffey L, Emery C. What are the risk factors for groin strain injury in sport? A systematic review of the literature. Sports Med 2007; 37: 881-94.

[29] Kalebo P, Karlsson J, Sward L, Peterson L. Ultrasonography of chronic tendon injuries in the groin. Am J Sports Med 1992; 20: 634-9.

[30] Brennan D, O'Connell MJ, Ryan M, et al. Secondary cleft sign as a marker of injury in athletes with groin pain: MR image appearance and interpretation. Radiology 2005; 235: 162-7.

[31] Robinson P, Barron DA, Parsons W, Grainger AJ, Schilders EM, O'Connor PJ. Adductor-related groin pain in athletes: correlation of MR imaging with clinical findings. Skeletal Radiol 2004; 33: 4517.

[32] Briggs RC, Kolbjornsen PH, Southall RC. Osteitis pubis, Tc-99m MDP, and professional hockey players. Clin Nucl Med 1992; 17 : 861-3.

[33] Gibbon WW, Hession PR. Diseases of the pubis and pubic symphysis: MR imaging appearances. AJR Am J Roentgenol 1997; 169: 849-53.

[34] Verrall GM, Henry L, Fazzalari NL, Slavotinek JP, Oakeshott RD. Bone biopsy of the parasymphyseal pubic bone region in athletes with chronic groin injury demonstrates new woven bone formation consistent with a diagnosis of pubic bone stress injury. Am J Sports Med 2008; 36: 2425-31.
[35] Malycha P, Lovell G. Inguinal surgery in athletes with chronic groin pain: the 'sportsman's' hernia. Aust N Z J Surg 1992; 62: 1235.

[36] Hackney RG. The sports hernia: a cause of chronic groin pain. Br J Sports Med 1993; 27: 58-62.

[37] Holzheimer RG. Inguinal Hernia: classification, diagnosis and treatment--classic, traumatic and Sportsman's hernia. Eur J Med Res 2005;10:121-34.

[38] MacLeod DA, Gibbon WW. The sportsman's groin. Br J Surg 1999; 86: 849-50.

[39] Orchard JW, Read JW, Neophyton J, Garlick D. Groin pain associated with ultrasound finding of inguinal canal posterior wall deficiency in Australian Rules footballers. Br J Sports Med 1998; 32: 134-9.

[40] LeBlanc KE, LeBlanc KA. Groin pain in athletes. Hernia 2003; 7 : 68-71.

[41] Nguyen JT, Peterson JS, Biswal S, Beaulieu CF, Fredericson M. Stress-related injuries around the lesser trochanter in long-distance runners. AJR Am J Roentgenol 2008;190:1616-20.

[42] Deutsch AL, Coel MN, Mink JH. Imaging of stress injuries to bone. Radiography, scintigraphy, and MR imaging. Clin Sports Med 1997; 16: 275-90.

[43] Spitz DJ, Newberg AH. Imaging of stress fractures in the athlete. Radiol Clin North Am 2002; 40: 313-31.

[44] Brittenden J, Robinson P. Imaging of pelvic injuries in athletes. $\mathrm{Br}$ J Radiol 2005; 78: 457-68.

[45] Gaeta M, Minutoli F, Scribano E, et al. CT and MR imaging findings in athletes with early tibial stress injuries: comparison with bone scintigraphy findings and emphasis on cortical abnormalities. Radiology 2005; 235: 553-61.

[46] Slocum KA, Gorman JD, Puckett ML, Jones SB. Resolution of abnormal MR signal intensity in patients with stress fractures of the femoral neck. AJR Am J Roentgenol 1997; 168: 1295-9.

[47] Lee JK, Yao L. Stress fractures: MR imaging. Radiology 1988;169. 217-20.

[48] Zarins B, Ciullo JV. ACute muscle and tendon injuries in athletes. Clin Sports Med 1983; 2: 167-82.

[49] Wootton JR, Cross MJ, Holt KW. Avulsion of the ischial apophysis. The case for open reduction and internal fixation. J Bone Joint Surg Br 1990; 72: 625-7.

[50] Peck DM. Apophyseal injuries in the young athlete. Am Fam Physician 1995; 51: 1891-5, 1897-8.

[51] Cardinal E, Buckwalter KA, Capello WN, Duval N. US of the snapping iliopsoas tendon. Radiology 1996;198: 521-2.

[52] Jacobson T, Allen WC. Surgical correction of the snapping iliopsoas tendon. Am J Sports Med 1990;18: 470-4.

[53] Gruen GS, Scioscia TN, Lowenstein JE. The surgical treatment of internal snapping hip. Am J Sports Med 2002; 30: 607-13.

[54] Kagan A, 2nd. Rotator cuff tears of the hip. Clin Orthop Relat Res 1999; (368): 135-40.

[55] Raman D, Haslock I. Trochanteric bursitis--a frequent cause of 'hip' pain in rheumatoid arthritis. Ann Rheum Dis 1982; 41: 602-3.

[56] Bird PA, Oakley SP, Shnier R, Kirkham BW. Prospective evaluation of magnetic resonance imaging and physical examination findings in patients with greater trochanteric pain syndrome. Arthritis Rheum 2001; 44: 2138-45.

[57] Bywaters EG. The bursae of the body. Ann Rheum Dis 1965; 24: 215-8.

[58] Kingzett-Taylor A, Tirman PF, Feller J, et al. Tendinosis and tears of gluteus medius and minimus muscles as a cause of hip pain: MR imaging findings. AJR Am J Roentgenol 1999;173: 1123-6.

[59] Chung CB, Robertson JE, Cho GJ, Vaughan LM, Copp SN, Resnick D. Gluteus medius tendon tears and avulsive injuries in elderly women: imaging findings in six patients. AJR Am J Roentgenol 1999;173: 351-3.

[60] Gordon EJ. Trochanteric bursitis and tendinitis. Clin Orthop 1961; 20:193-202.

[61] Varma DG, Richli WR, Charnsangavej C, Samuels BI, Kim EE, Wallace S. MR appearance of the distended iliopsoas bursa. AJR Am J Roentgenol 1991; 156: 1025-8.

[62] Blankenbaker DG, De Smet AA, Keene JS. Sonography of the iliopsoas tendon and injection of the iliopsoas bursa for diagnosis and management of the painful snapping hip. Skeletal Radiol 2006; 35: 565-71.

[63] Johnston CA, Wiley JP, Lindsay DM, Wiseman DA. Iliopsoas bursitis and tendinitis. A review. Sports Med 1998; 25: 271-83. 
[64] Petersilge CA. From the RSNA Refresher Courses. Radiological Society of North America. Chronic adult hip pain: MR arthrography of the hip. Radiographics 2000; 20 Spec No: S43-52.

[65] Newman JS, Newberg AH. MRI of the painful hip in athletes. Clin Sports Med 2006; 25: 613-33.

[66] McCarthy JC, Busconi B. The role of hip arthroscopy in the diagnosis and treatment of hip disease. Can J Surg 1995; 38 (Suppl 1): S13-7.

[67] McCarthy JC, Busconi B. The role of hip arthroscopy in the diagnosis and treatment of hip disease. Orthopedics 1995;18: 7536.

[68] Notzli HP, Wyss TF, Stoecklin CH, Schmid MR, Treiber K, Hodler $\mathrm{J}$. The contour of the femoral head-neck junction as a predictor for the risk of anterior impingement. J Bone Joint Surg Br 2002; 84: 556-60.

[69] Ito K, Minka MA, 2nd, Leunig M, Werlen S, Ganz R. Femoroacetabular impingement and the cam-effect. A MRI-based quantitative anatomical study of the femoral head-neck offset. J Bone Joint Surg Br 2001; 83: 171-6.
[70] Jager M, Wild A, Westhoff B, Krauspe R. Femoroacetabular impingement caused by a femoral osseous head-neck bump deformity: clinical, radiological, and experimental results. J Orthop Sci 2004; 9: 256-63.

[71] Wenger DE, Kendell KR, Miner MR, Trousdale RT. Acetabular labral tears rarely occur in the absence of bony abnormalities. Clin Orthop Relat Res 2004:145-50.

[72] Kassarjian A, Yoon LS, Belzile E, Connolly SA, Millis MB, Palmer WE. Triad of MR arthrographic findings in patients with cam-type femoroacetabular impingement. Radiology 2005; 236: 588-92.

[73] Klaue K, Durnin CW, Ganz R. The acetabular rim syndrome. A clinical presentation of dysplasia of the hip. J Bone Joint Surg Br 1991; 73: 423-9.

[74] Tannast M, Goricki D, Beck M, Murphy SB, Siebenrock KA. Hip damage occurs at the zone of femoroacetabular impingement. Clin Orthop Relat Res 2008; 466: 273-80.

(C) MacMahon et al.; Licensee Bentham Open.

This is an open access article licensed under the terms of the Creative Commons Attribution Non-Commercial License (http://creativecommons.org/licenses/by-nc/3.0/) which permits unrestricted, non-commercial use, distribution and reproduction in any medium, provided the work is properly cited. 